\title{
A Facile, Fast, and Low-Cost Method for Fabrication of Micro/ Nano-Textured Superhydrophobic Surfaces
}

Amir Esmaeili

Virginia Commonwealth University

Noshin Mir

Reza Mohammadi

Follow this and additional works at: https://scholarscompass.vcu.edu/gradposters

Part of the Mechanical Engineering Commons

\section{Downloaded from}

Esmaeili, Amir; Mir, Noshin; and Mohammadi, Reza, "A Facile, Fast, and Low-Cost Method for Fabrication of Micro/Nano-Textured Superhydrophobic Surfaces" (2020). Graduate Research Posters. Poster 68. https://scholarscompass.vcu.edu/gradposters/68

This Poster is brought to you for free and open access by the Graduate School at VCU Scholars Compass. It has been accepted for inclusion in Graduate Research Posters by an authorized administrator of VCU Scholars Compass. For more information, please contact libcompass@vcu.edu. 


\section{A Facile, Fast, and Low-Cost Method for Fabrication of Micro/Nano-Textured Superhydrophobic Surfaces}

Amir R. Esmaeili, Noshin Mir, Reza Mohammadi

Department of Mechanical and Nuclear Engineering, Virginia Commonwealth University, Richmond, VA

\section{Abstract}

Alkyl ketene dimer (AKD) is frequently used in paper industry as an inexpensive sizing agent. The formation of a porous structure after curing the solidified AKD for four days results in superhydrophobicity. We utilized, a facile and low-cost method to turn AKD's surface superhydrophobic in $<10 \mathrm{~min}$. We fabricated superhydrophobic coatings by dipping glass and paper substrates in molten $\mathrm{AKD}$ at $40^{\circ} \mathrm{C}$ for $3 \mathrm{~min}$ and then treating them with ethanol after solidification. Moreover, the advancing and receding contact angles significantly increased from $92.9 \pm 3.0$ and $78.4 \pm 4.7^{\circ}$ to $158.7 \pm 1.4$ and $156.8 \pm 0.9^{\circ}$, respectively. This increase in superhydrophobicity is due to the formation of porous, entangled irregular micro/nano textures that create air cushions on the surface resulting in droplet state transition from Wenzel to Cassie.

\section{Method}

$\begin{gathered}\text { Isothermally } \\
\text { heating AKD at } \\
40^{\circ} \mathrm{C} \text { for } 3 \mathrm{~min}\end{gathered}$
Dip-coating the
sample in
molten AKD $\Rightarrow$\begin{tabular}{c}
$\begin{array}{c}\text { Treating the } \\
\text { solidified AKD } \\
\text { with ethanol }\end{array}$ \\
\hline
\end{tabular}

The samples were characterized by X-ray diffraction (XRD), Scanning electron microscopy (SEM), Fourier transform-infrared spectroscopy (FT-IR), X-ray photoelectron spectroscopy (XPS), and Confocal laser scanning microscopy (CLSM). In addition, in order to measure the mean diameter and fraction of pores on the surface of AKD coatings, the SEM images were analyzed with an image-processing software (ImageJ 1.52a). Also, advancing and receding contact angles were measured for 9 randomly-chosen spots on each sample with the liquid increase/decrease method by using a drop shape analyzer (DSA25E, Krüss, Germany)
Role of ethanol treatment

The role of ethanol is to dissolve the smooth structures containing monomers and help nano-patterns to separate and stand out. This promotes the increase of pores fraction, which is beneficial for improving the superhydrophobic properties of the surface. Based on the FT-IR results, it was seen that neither ethanol treatment nor long curing process of AKD has a noticeable impact on the functional groups of the as-solidified AKD. Furthermore, XPS results also were entirely in agreement with FT-IR results and revealed that there are no noticeable changes in the chemical bonds in this process.

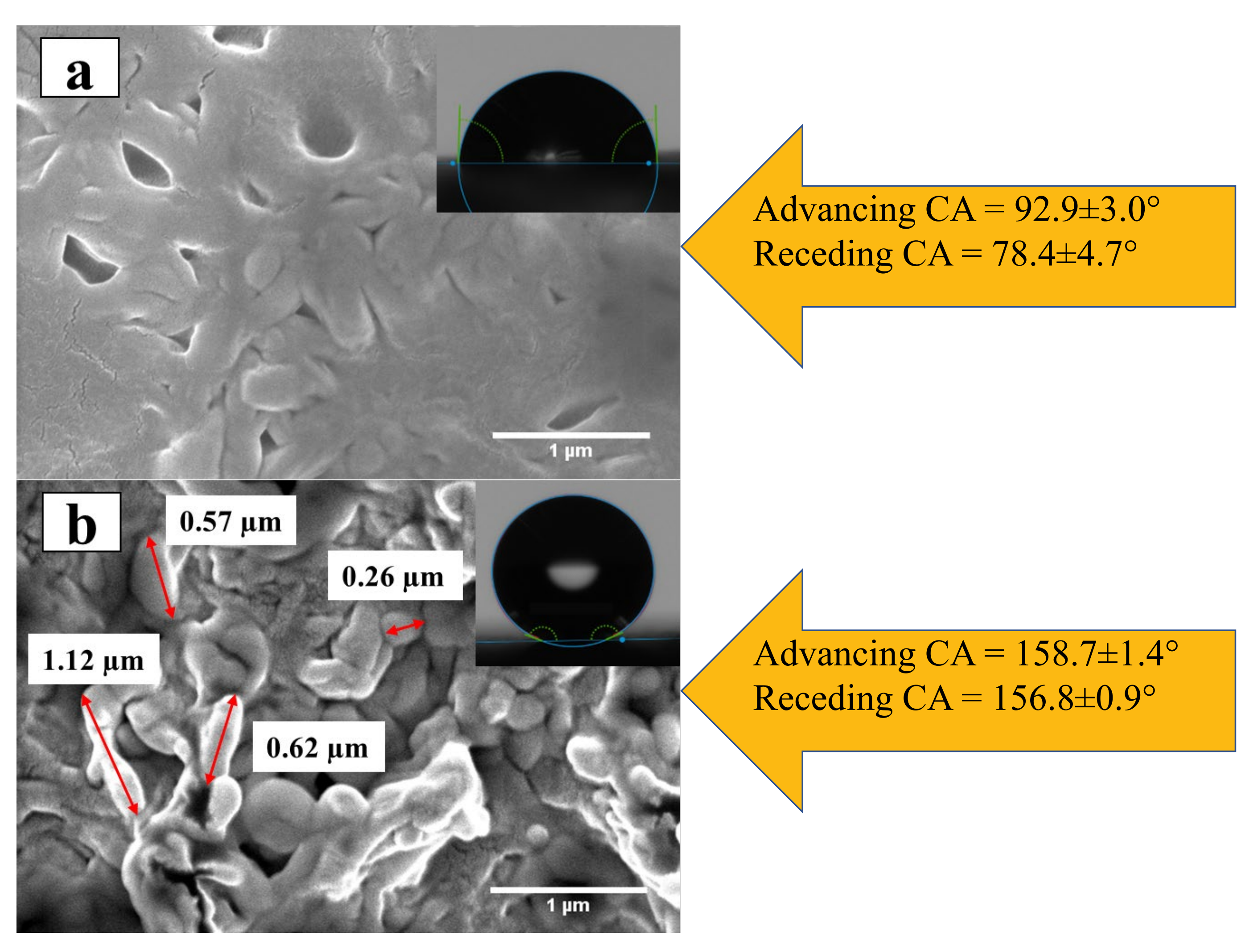

Figure 1. SEM images of AKD coatings prepared from a $40^{\circ} \mathrm{C}$ melt, isothermally heated for $3 \mathrm{~min}$ : (a) with no post-solidification modifications, and (b) solid coating was treated with ethanol. Insets: water droplet on the sample.
Impact of heating time and temperature of the melt

We increased the temperature of the melt from 40 to $70^{\circ} \mathrm{C}$ (held isotherm for $3 \mathrm{~min}$ ) and treated the sample with ethanol after solidification. It is seen that the advancing and receding contact angles are $160.5 \pm 1.1$ and $158.5 \pm 1.5^{\circ}$, respectively; therefore, the molten AKD's temperature plays an important role in the wettability of the samples. In order to make the sample with the highest dynamic contact angles, we optimized the values of AKD's melt temperature, melt isothermal holding time, and ethanol treatment.
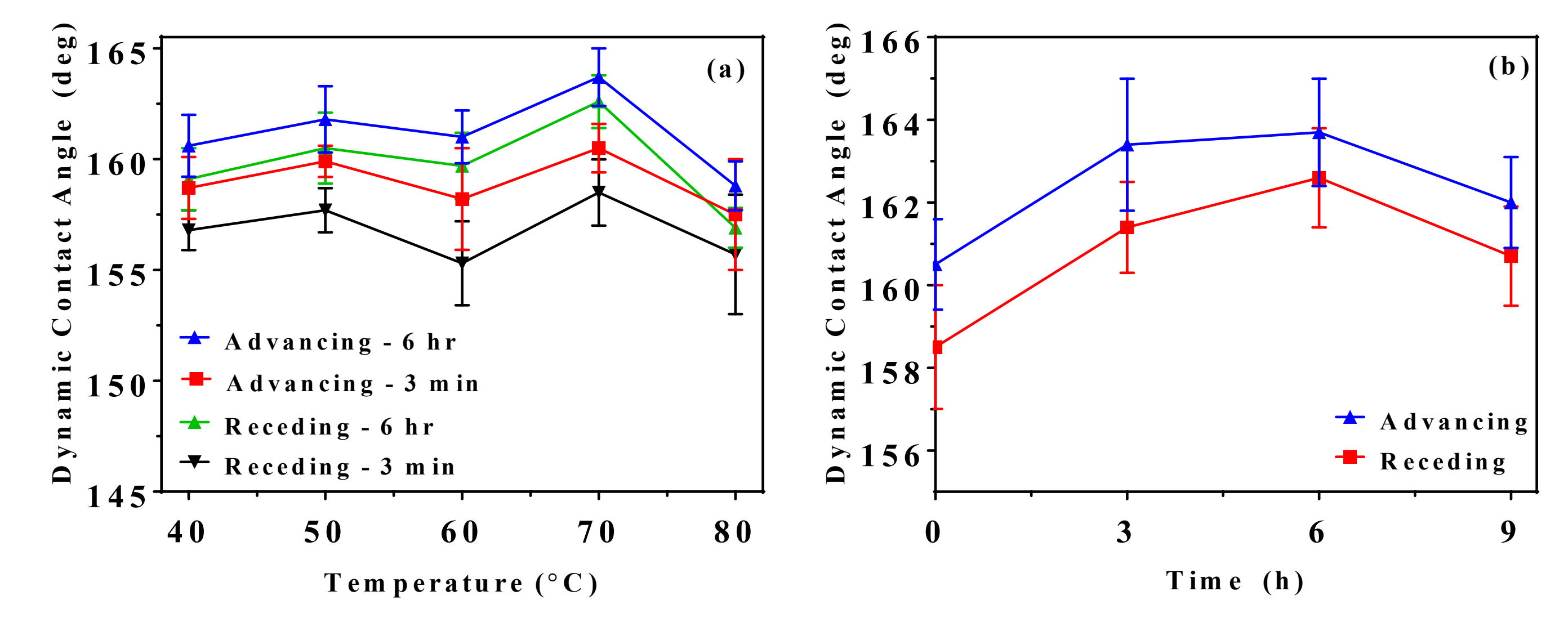

Figure 2. Advancing and receding contact angles of ethanol-treated solidified AKD from: (a) isothermally heated melt at 40 to $80^{\circ} \mathrm{C}$ for $3 \mathrm{~min}$ and $6 \mathrm{~h}$, and (b) isothermally heated melt at $70^{\circ} \mathrm{C}$ for $3 \mathrm{~min}, 3 \mathrm{~h}, 6 \mathrm{~h}$ and $9 \mathrm{~h}$.

Flexibility of our facile method

Besides ethanol, this technique was also demonstrated to be working with some other organic solvents such as methanol and isopropanol. In addition to glass, our method seems to also work for other substrates including paper.

\section{References}

A.R. Esmaeili, N. Mir, R. Mohammadi, A Facile, Fast, and Low-Cost Method for Fabrication of Micro/Nano-Textured Superhydrophobic Surfaces, J. Colloid Interface Sci. (2020). https://doi.org/https://doi.org/10.1016/j.jcis.2020.04.027. 